\title{
El DERECHO INTERNACIONAL ANTE LA OCUPACIÓN DE LOS TERRITORIOS PALESTINOS Y EL MURO DE SEPARACIÓN
}

\author{
Juan Manuel PORTILlA GÓMEZ*
}

RESUMEN: Los territorios palestinos conquistados por Israel en 1967, constituyen la mayor ocupación registrada y su población ha sufrido un sinnúmero de vejaciones resultantes de la inobservancia israelí del derecho internacional. Aunado a ello, Israel lleva a cabo la construcción de un muro que aísla a comunidades palestinas enteras y modifica las fronteras reconocidas entre Palestina e Israel en beneficio de éste. Ante esto, la Corte Internacional de Justicia, a solicitud de la Asamblea General de la ONU, ha dictado una opinión consultiva en la que declara ilegal dicho muro y señala las consecuencias derivadas de dicho ilícito. Así, el máximo tribunal internacional hace una valiosa aportación respecto al régimen jurídico aplicable a Palestina y contribuye de manera importante a definir el derecho de ocupación.

ABSTRACT: The Palestinian territories overtook by Israel in 1967 constitute the major occupation ever, generating a constant suffering of the population of Palestine because of the great deal of mistreatment against them, as a result of Israel's nonobservance of International Law. Following this, Israel carries out the construction of a wall that separates the whole Palestinian communities and modifies the recognized limits between Palestine and Israel in favor of the latter. With this respect, the International Court of Justice, as a petition made by the UN General Assembly, issued an advisory opinion in which it declares that such wall is illicit, and it points out the consequences that would derive from this unlawful action. This way, the highest international tribunal makes a worthy contribution to the legal regime applicable to Palestine and it makes a significant advance towards the definition of occupation law.

RÉSUMÉ: Les territoires Palestines conquéris par Israel en 1967, sont la majeur occupation constaté, et la population a souffri plusieurs des vexations comme resultat de l'inobservance israélienne du droit international. Ainsi, l'Israël est en construant un mur que mis á l'écart les communités palestines complétamment et change les frontiéres reconnues entre Palestine et Israël au bénefice du derniére. Étant donné ca, la Cour Internationale de Justice, à la demande d'Assemblé Genérale des Nations Unies, a édicté une opinion consultative dans laquelle ce mur s'est declaré illégal, et montre les consequénces découlés de cet action. Ensuite, le plus haute tribunal international fait une précieuse contribution au régime juridique applicable a Palestine et a aide à la definition du droit de l'occupation.

* Doctor en derecho internacional. Profesor de carrera de tiempo completo en la Facultad de Estudios Superiores Acatlán de la UNAM.

Anuario Mexicano de Derecho Internacional, vol. VI, 2006, pp. 345-375 
SUMARIO: I. Introducción. II. Aplicación del derecho internacional a la ocupación israelí. III. El Cuarto Convenio de Ginebra como derecho consuetudinario. IV. Aplicación del derecho de los derechos humanos en los territorios palestinos ocupados. V. El muro israelí en territorio palestino. VI. La opinión consultiva de la Corte Internacional de Justicia. VII. Conclusiones.

\section{INTRODUCCIÓN}

Al final de la llamada Guerra de los Seis Días, en 1967, Israel asumió el control de los llamados territorios palestinos. ${ }^{1}$ La Ribera Occidental, conocida también como Cisjordania, es un área, previamente bajo administración jordana, situada entre el río Jordán e Israel. En diciembre de 1967, el gobierno militar israelí emitió una ordenanza señalando que para todo propósito el término "región de Judea y Samaria" significaría exactamente lo mismo que el término "región de la Ribera Occidental". Este cambio en la terminología se derivó del apego bíblico de Israel sobre estas zonas y al rechazo de soberanía jordana sobre esta zona. Los acuerdos de Camp David, firmados en 1978 por Egipto e Israel, incluían disposiciones para una "autoridad autónoma" en la Ribera Occidental y Gaza pero nunca entraron en vigor. ${ }^{2}$

Entre 1948 y 1967, la franja de $\mathrm{Gaza}^{3}$ fue administrada por Egipto, sin que éste hiciera ningún reclamo de soberanía. A su vez, Jerusalén Oriental formaba parte de la Ribera Occidental pero fue sometido a la

1 Si bien la cuestión palestina se remonta a la disolución del imperio turco otomano y al mandato británico sobre esta nación en 1922, la ocupación de Israel se da al término de la Guerra de 1967. Para un exhaustivo análisis jurídico del mandato británico y su prolongación como derecho positivo, Véase Boyle, Francis. A., Palestine, Palestinians and International Law, Clarity Press, Atlanta, 2003, pp. 26-28.

2 Roberts, A., "Prolongued Military Occupation: The Israeli-Occupied Territories 1967-1968”, en Palyfair, E. (ed.), International Law and Administration of Occupied Territories, Oxford, Clarendon Press, 1992, 25, at 40.

3 El Gabinete de Israel aprobó el 20 de febrero del 2005 el plan de retiro de Gaza, mismo que había sido aprobado por el Knesset el 16 del mismo mes. Este plan es una medida unilateral propuesta por Ariel Sharon e implica el desmantelamiento total de las colonias israelíes, a partir del 20 de julio y concluirá a finales del 2005. 
autoridad israelí, con límites ampliados, el 28 de junio de 1967, siendo formalmente anexado el 30 de julio de $1980 .^{4}$

No obstante que las leyes sobre el estatus de Jerusalén Oriental y las alturas del Golán no utilizan la palabra "anexión", estas zonas fueron puestas directamente bajo jurisdicción israelí mediante acciones equivalentes a la anexión. Ambas zonas siguen considerándose por la comunidad internacional como ocupadas, y el estatus respecto a la aplicación de normas internacionales es en la mayoría de los casos idéntica al de la Ribera Occidental y Gaza. ${ }^{5}$

La ocupación israelí de esos territorios, desde 1967, contradice el supuesto de que la ocupación es temporal en esencia. Sin embargo, algunas regiones como el Sinaí ${ }^{6}$ y partes del Golán ${ }^{7}$ han sido devueltas después de haber permanecido bajo su control por largo tiempo.

La ocupación por Israel de los territorios palestinos lleva casi cuatro décadas de existencia y además de sus acciones contrarias al derecho internacional durante este tiempo, ahora se suma la construcción, en su mayor parte abarcando la Ribera Occidental, de un muro al que llama valla de seguridad y que en realidad constituye una indebida partición y aislamiento de comunidades palestinas enteras. Esto, además de alterar las fronteras internacionales reconocidas constituye una grave violación al derecho internacional humanitario y representa mayores sufrimientos a la población.

A partir del planteamiento de las doctrinas israelíes que pretenden justificar la retención y/o anexión de los citados territorios, en el presente trabajo se busca demostrar su inconsistencia y falta de validez. Asimismo, de acuerdo con el derecho consuetudinario y convencional, se probará la pertinencia del derecho humanitario aplicable, por vía del Cuarto Convenio de Ginebra, así como de los instrumentos de derechos humanos. En este sentido, reviste enorme importancia el que se haya emitido

4 La anexión fue a través de la Ley Básica: Jerusalén, Capital de Israel, 30 de julio de 1980 Laws of Israel, 1980, p. 209.

5 Véanse las resoluciones de la Asamblea General y el Consejo de Seguridad listadas con detalle en Roberts, "Prolongued...", cit., nota 2 (en notas 71,77-79 y 133).

6 La península del Sinaí quedó bajo control israelí en 1967. Israel se retiró gradualmente, primero con los acuerdos de repliegue de 1974 y 1975, y luego conforme al Tratado de Paz con Egipto que estableció un calendario para el retiro total, por fases, concluido el 25 de abril de 1982.

7 Las Alturas del Golán, pertenecientes a Siria, pasaron a control israelí después de 1967. En la guerra de 1973, Israel obtuvo territorio adicional en esa zona. Tras el acuerdo de repliegue de 1974, Israel se retiró del territorio adicional, así como de otras áreas ocupadas en 1967. La jurisdicción israelí se hizo extensiva a las alturas del Golán el 14 de diciembre de 1981. 
una opinión consultiva en esta materia por la Corte Internacional de Justicia, a solicitud de la Asamblea General de las Naciones Unidas, debido a que es la primera vez que las consecuencias jurídicas de la ocupación israelí son analizadas bajo la lupa de un tribunal internacional. En nuestro estudio, dicha resolución cierra el círculo del análisis en torno a la ilegal ocupación israelí de los territorios palestinos.

\section{APLICACIÓN DEL DERECHO INTERNACIONAL A LA OCUPACIÓN ISRAELÍ ${ }^{8}$}

Israel, Egipto, Jordania y Siria, Estados directamente involucrados, están formalmente vinculados por los principales acuerdos que regulan la ocupación. Ninguno de ellos es parte de la Cuarta Convención de La Haya de 1907. Sin embargo, en virtud del carácter de derecho consuetudinario del Reglamento anexo a la convención, todos están obligados por éste. Israel y Jordania ratificaron las cuatro convenciones de Ginebra de 1949 en 1951. Egipto y Siria hicieron lo propio en 1952 y 1953, respectivamente. Egipto ratificó la Convención de La Haya sobre Propiedad Cultural y su Protocolo en 1955, Jordania ratificó ambas en 1957 y Siria las dos instrumentos en 1958. Israel ratificó la Convención en 1957 y se adhirió al Protocolo en 1958. Israel no reconoció los Protocolos de Ginebra de 1977, Egipto los ratificó en 1992, Jordania en 1979 y Siria accedió al Protocolo en 1983. ${ }^{9}$ Por su parte, la Organización de Liberación de Palestina (OLP), a nombre del Estado de Palestina, ${ }^{10}$ se adhirió a los cuatro Convenios de Ginebra de 1949 y a los adicionales de 1977 efectuando el trámite correspondiente ante el gobierno de Suiza, el cual es depositario de dichos tratados. Debido a las presiones de Estados Unidos, el gobierno suizo no aceptó formalmente el instrumento de adhesión de Palestina. $^{11}$

8 Para una perspectiva en detalle del derecho internacional de la ocupación, Véase Portilla Gómez, Juan Manuel, "El derecho internacional humanitario y el régimen jurídico aplicable a la ocupación de Iraq”, en Becerra Ramírez, Manuel (coord.), Aspectos jurídico-políticos de la guerra de Iraq, México, UNAM, Instituto de Investigaciones Jurídicas, 2005, pp. 183-188.

9 Roberts, A. y Guelff, R., Documents on the Laws of War, Oxford University Press, 2000, pp. 258, 403 y 493.

10 El 15 de noviembre de 1988, el Consejo Nacional Palestino, reunido en Argel, proclamó la Declaración de Independencia Palestina. Véase Boyle, Francis, op. cit., nota 1, pp. 41-46

11 Ibidem, p. 20 
La principal dificultad en torno a la aplicación del derecho internacional humanitario ha sido el rechazo de los Estados a aceptar las convenciones en situaciones donde deben aplicarse con claridad. Los intentos para justificar tales negativas han estado a menudo basados en diferencias entre conflictos específicos en una situación determinada y aquellos para los cuales estas convenciones fueron teóricamente adoptadas. Hay de hecho, muchas situaciones en que la aplicación de los Convenios de Ginebra ha sido negada de tal forma que se ha rechazado el derecho más que su reconocimiento formal y su instrumentación. ${ }^{12}$ Como indica Baxter, "la primera línea de defensa es negar que aplica a todo". ${ }^{13}$ Como ejemplos tenemos la ocupación indonesia de Timor Oriental, la ocupación soviética de Afganistán y la ocupación iraquí de Kuwait.

\section{El debate legal sobre la aplicación del Cuarto Convenio de Ginebra a los territorios palestinos}

Desde octubre de 1967, Israel ha asumido consistentemente la posición de que el Cuarto Convenio de Ginebra no es aplicable de jure a la Ribera Occidental y a la Franja de Gaza. Al sostener esta posición, Israel se ha basado en la teoría del "sucesor ausente" teoría inicialmente planteada por Blum. ${ }^{14}$ Esta teoría está basada en dos argumentos que aunque independientes uno del otro se relacionan entre sí. El primero de ellos parte de una singular interpretación del artículo 2 común de los Convenios de Ginebra que indica en sus dos primeros párrafos:

Aparte de las disposiciones que deben entrar en vigor ya en tiempo de paz, el presente Convenio se aplicará, en caso de guerra declarada o de cualquier otro conflicto armado que surja entre dos o varias de las Altas Partes Contratantes, aunque una de ellas no haya reconocido el estado de guerra.

12 Meron, T., Human Rights in Internal Strife: The International Protection, Cambridge, Grotious Publications, 1987, p. 16.

13 Baxter, "Some Existing Problems of Humanitarian Law", en varios autores, The Concept of International Armed Conflict Further Outlook, Proceedings of the International Symposium on Humanitarian Law, Bruselas, 1974, p. 2.

14 Blum, Y., "The Missing Reversioner: Reflections on the Status of Judea and Samaria", Israel Law Review, núm. 3, 1968, p. 279 
El Convenio aplicará también en todos los casos de ocupación total o parcial del territorio de una Alta Parte Contratante, aunque tal ocupación no encuentre resistencia militar.

\section{A. La teoría del "sucesor ausente"}

Al aseverar que el propósito del derecho de ocupación beligerante es proteger los derechos de un soberano saliente, se argumenta que estos territorios no eran parte de Jordania ni Egipto antes de 1967 de modo que no puede afirmarse que constituyan el "territorio de una Alta Parte Contratante" bajo el artículo 2 común, haciendo así totalmente inaplicable el Cuarto Convenio de Ginebra. ${ }^{15}$ De acuerdo con este argumento, la presencia de Israel en la Ribera Occidental y la Franja de Gaza no es una ocupación sino una "administración" en ausencia de un soberano, sin relación con el Cuarto Convenio de Ginebra y con el derecho de ocupación en general. ${ }^{16}$ Israel expresó que si aceptaba la aplicación automática del convenio, estaría reconociéndoles a Egipto y Jordania el carácter de soberanos removidos con derechos de sucesión. ${ }^{17}$

La interpretación israelí se basa en un error técnico. Referirse al segundo párrafo del artículo 2 común es inapropiado, toda vez que es el primer párrafo el que aplica cuando una ocupación comienza durante una guerra. Este párrafo para nada indica "el territorio de una Alta Parte Contratante" refiriéndose solamente a "todos los casos de guerra declarada o cualquier otro conflicto armado que surja entre dos o varias de las Altas Partes Contratantes". ${ }^{18}$ Objeciones similares podrían haberse hecho acerca de la aplicación del Reglamento de La Haya que contiene una disposición similar de que el territorio ocupado es "territorio de un estado enemigo". Asimismo, esta interpretación ignora los precedentes de la aplicación formal del derecho de guerra aún en situaciones que difieran en alguna forma de las condiciones establecidas por el Reglamento de La Haya y los Convenios de Ginebra. Por otra parte, la interpretación israelí nunca se ha planteado respecto a los territorios ocupados del Sinaí y el

15 Imseis, A., "On the Fourth Geneva Convention and the Occupied Palestinian Territory", Harvard International Law Journal, núm. 44, p. 81.

16 Falk, R. A. y Weston, B. H., "The Relevance of International Law to Israeli and Palestinian Rights", en Playfair, E. (ed.), International Law and Administration, p. 131.

17 Véase Blum, Y., "The Missing Reversioner: Reflections on the Status of Judea and Samaria", Israel Journal Law Review, núm. 3, 1968, p. 279.

18 Roberts, "Prolongued...", cit., nota 2, p. 47 
Golán cuyo estatus previo a 1967 no fue disputado por Israel y los cuales eran claramente "territorio de una Alta Parte Contratante".

\section{B. Conquista defensiva}

El segundo argumento de la teoría del sucesor ausente señala que Israel posee un mejor título sobre los territorios ocupados de Palestina que Egipto y Jordania, con base en la noción de "conquista defensiva". Según ésta, se afirma que Israel asumió el control de los territorios palestinos en 1967 en una guerra defensiva contra Egipto y Jordania, mismos que carecían de título legal sobre ese territorio, equiparándose así el control del territorio a un título legal válido. ${ }^{19}$ Blum concluye que, "Israel no puede considerarse como una potencia ocupante conforme al sentido dado a este término en derecho internacional en ninguna parte del mandato sobre Palestina, incluyendo Judea y Samaria”. ${ }^{20}$

\section{Contra argumentos}

Estas posiciones israelíes han tratado de determinar el marco legal y político en torno a los territorios ocupados y requieren ser analizadas. Pueden utilizarse diversos argumentos para rebatir la teoría de Blum. Respecto a la cuestión de que el legítimo soberano debe ser desplazado por el ocupante beligerante, no hay evidencia de que el término "territorio de una Alta Parte Contratante" tal como se utiliza en el artículo 2 común de los Convenios de Ginebra se refiera solamente al título legal total como legítimo soberano. Es ampliamente aceptado que el término "territorio" fue utilizado por los redactores de los convenios para indicar, además del título de jure, un mero título de facto sobre el territorio". ${ }^{21} \mathrm{Si}$ la situación fuera diferente, cualquier ocupante beligerante podría eludir sus obligaciones bajo el convenio oponiéndose a la validez del título de la potencia desplazada sobre el territorio. Esta noción no encuentra sustento ni en el texto del convenio ni en los trabajos preparatorios de éste.

19 Imseis, op. cit., nota 15 , p. 82

20 The Colonization of the West Bank Territories by Israel: Hearing Befote the Subcommittee on Immigration and Naturalization of the Senate Committee on the judiaciary, 95th. Congress 35, 1978 (declaración de Yehuda Blum, traducción del autor).

21 Mallison, S. V. y Mallison, W. T., The Palestinian Problem in International and World Order, Harlow, 1986, p. 254. 
Otra descalificación de la teoría del sucesor ausente es que ignora el efecto del derecho internacional sobre la libre determinación de los pueblos. Un principio clave del mismo es que la soberanía reside en el pueblo de un Estado y no en sus elites gobernantes. Algunos autores afirman que este principio es de ius cogens. ${ }^{22}$ El rechazo de Blum a la posibilidad de que el pueblo palestino pueda constituirse en el legítimo sucesor en dichos territorios invalida su teoría y debilita la posición de Israel por su apego a la misma, sobre todo considerando que el derecho del pueblo palestino ha sido largamente reconocido por la comunidad internacional. ${ }^{23}$ Por ello, se ha asumido ampliamente que los territorios palestinos ocupados constituyen la unidad territorial en donde se establecerá el Estado palestino.

De manera similar, la afirmación de que el convenio no puede aplicarse debido a que el control del territorio por la potencia desalojada fue resultado de una agresión ilícita lleva a una conclusión absurda. Implica que en virtud de que los habitantes de la Ribera Occidental fueron víctimas de una agresión jordana en 1948, éstos pueden ser nuevamente víctimas al negárseles la protección humanitaria del convenio bajo la ocupación israelí. ${ }^{24}$ Como señala Mallison, "si el derecho humanitario fuera interpretado de tal modo que su aplicación dependiese de la aceptación del ocupante beligerante de la legitimidad o el carácter no agresivo de los objetivos militares de su adversario, es claro que ese ordenamiento nunca se aplicaría". ${ }^{25}$ Esta parte de la teoría de Blum no es convincente en tanto deja todo a discreción del ocupante beligerante y "frustra la totalidad del propósito humanitario" del Cuarto Convenio de Ginebra cuyo objetivo es proteger los intereses de las personas civiles en tiempos de guerra, no los intereses de los gobiernos. ${ }^{26}$

Respecto a la pretensión sobre el título de territorio ocupado con base en la "conquista defensiva", las acciones de Israel no fueron del todo defensivas. Archivos oficiales muestran como los líderes israelíes sabían que no enfrentaban una amenaza inminente de una agresión armada que justificara un ataque preventivo en contra de Egipto. ${ }^{27}$ Aún asu-

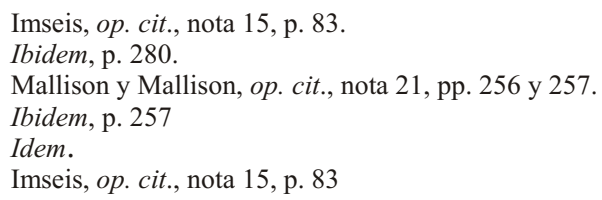


miendo que las acciones de Israel en 1967 fueran defensivas, la teoría de Blum pasa por alto el principio de ius cogens de que la adquisición de territorio mediante la amenaza o uso de la fuerza es inadmisible. Esto es consistente con la supresión en el derecho internacional del derecho de conquista y con el surgimiento del derecho de ocupación beligerante, así la adquisición territorial es temporal por naturaleza y conlleva el deber implícito de retirarse una vez que las hostilidades hayan cesado. ${ }^{28} \mathrm{El}$ derecho internacional relativo al uso de la fuerza en legítima defensa no permite a un Estado adquirir territorio a través del uso de tal recurso. ${ }^{29}$ En esencia, el concepto de "conquista defensiva" es inexistente en el derecho internacional contemporáneo. ${ }^{30}$

Más aún, el argumento basado en la soberanía bajo el artículo 2 no impide la aplicación del convenio conforme al artículo 4, el cual define a las personas protegidas como aquellas que se encuentran en manos de una potencia ocupante de la cual no son nacionales. Este convenio fue hecho, y debe interpretarse así, como un instrumento protector de la población y no del territorio. ${ }^{31}$

\section{La comunidad internacional}

Esta posición está sustentada por el hecho de que la casi totalidad de la comunidad internacional considera que el Cuarto Convenio de Ginebra aplica a la Ribera Occidental, incluyendo Jerusalén Oriental y la Franja de Gaza. Desde 1967, el Consejo de Seguridad ha emitido diversas resoluciones estableciendo la aplicación del Cuarto Convenio de Ginebra a los territorios palestinos ocupados, solicitándole a Israel el apego a sus términos como potencia ocupante. La Asamblea General ha emitido también cientos de resoluciones similares, muchas de ellas aprobadas por una mayoría abrumadora y constituyen por ello una clara evidencia de la opinión internacional en esta materia.

Asimismo, otras organizaciones intergubernamentales y no gubernamentales como la ONU, la Comisión de Derechos Humanos, la Comisión Internacional de Juristas y el Comité Internacional de la Cruz Roja se

28 Véase Falk y Weston, op. cit., nota 16, p. 134.

29 La Corte Internacional de Justicia desestimó la legítima defensa como justificación de la construcción del muro sobre Cisjordania.

30 Imseis, op. cit., nota 15, p. 83.

31 Boyd, S. M., "The Applicability of International Law to the Occupied Territories", Israel Yearbook of Human Rights, núm. 1, 1971, pp. 258-260. 
han pronunciado sobre este particular. El Comité Internacional de la Cruz Roja ha declarado consistentemente que el cuarto convenio es "aplicable in toto al territorio ocupado palestino" y que es inaceptable que "un tratado debidamente ratificado pueda suspenderse a capricho de una de las partes", o sea, Israel. ${ }^{32}$

Roberts señala que de hecho, Israel se ha metido en un embrollo por cuanto a la aplicación de las Convenciones de La Haya y Ginebra. ${ }^{33}$ Cita el argumento de Dinstein de que la ocupación beligerante continúa en tanto que el ocupante permanece en la zona y la guerra prosigue, y termina cuando el ocupante se retira de la zona al concluir la guerra ya sea con la victoria del ocupante o bien su derrota. ${ }^{34}$ Es en este sentido, que la Suprema Corte de Israel, en un juicio del 15 de marzo de 1979, indicó que la aplicación de dicho ordenamiento estaba condicionada a un estado de beligerancia. ${ }^{35}$ Sin embargo, desde el tratado de paz egipcio-israelí, no ha habido estado de beligerancia entre Egipto e Israel. Por ello, la Franja de Gaza, con mayor razón que antes, no ha sido "territorio de de un Estado enemigo". Aún así Israel ha seguido justificando sus poderes y acciones ahí refiriéndose al derecho de ocupación beligerante, si bien, como el mismo Dinstein lo reconoce, la fuente de la autoridad actual de Israel en la región no es un estado de guerra, sino lo convenido bajo el Tratado de Paz y los Acuerdos Marco de Camp David. ${ }^{36}$ Esto demuestra que Israel no tiene ningún problema en apartarse de su propia lógica según le convengan las normas y convenciones aplicables. ${ }^{37}$

\section{E. Aplicación de facto}

Los autores israelíes han argumentado que si el Cuarto Convenio de Ginebra es formalmente aplicable o no es un asunto académico debido a la señalada disposición para observar las "disposiciones humanitarias"

32 Comité Internacional de la Cruz Roja, Unsolved problems covered by the Fourth Convention, 1975 Annual Report, p. 22.

33 Roberts, "Prolongued...", cit., nota 2, p. 47.

34 Dinstein, Y., "The International Law of Belligerent Occupation and Human Rights", Israel Yearbook of Human Rights, núm. 8, 1978, pp. 104 y 105.

35 Caso Beit El, juicio HC 606/78 y 610/78.

36 Dinstein, Y., "The Israeli Supreme Court and the Law of Belligerant Occupation: Reunification of Families", Israel yearbook of Human Rights, núm. 18, 1988, pp. 174 y 175.

37 Roberts, "Prolongued...", cit., nota 2, p. 48. 
del convenio. ${ }^{38}$ Sin embargo, hay una gran diferencia entre la aplicación formal y la aplicación de facto. Una razón es que el término "disposiciones humanitarias" debe interpretarse en el sentido de que incluye todas las disposiciones. El problema radica en que precisamente Israel no acepta la totalidad de éstas y nunca ha señalando que disposiciones reconoce como humanitarias. Otra razón es que el rechazo de la aplicación formal del cuarto convenio ha sido frecuentemente mencionado en los procesos de la Corte Suprema israelí, y ha sido un factor determinante en la renuencia de los tribunales a basar sus decisiones en las disposiciones del mismo. ${ }^{39}$ La aplicación ex gratia del convenio por Israel podría verse como una forma unilateral de interpretar, e incluso abrogar, sus términos. ${ }^{40}$ Finalmente, es absurda la posición israelí de observar las "disposiciones humanitarias" en tanto que todas las disposiciones del convenio son humanitarias por definición.

La negativa de Israel a la plena aplicación de jure del Cuarto Convenio de Ginebra no es convincente y parece sólo una actitud de conveniencia. Ha sido criticada por muchos autores, y ha sido rechazada de forma decisiva por todos los miembros de la comunidad internacional a través de sus votos en las Naciones Unidas. ${ }^{41}$

\section{F. Ocupación prolongada ${ }^{42}$}

Otro factor esgrimido por Israel para justificar la no aplicación del Cuarto Convenio de Ginebra a los territorios palestinos es lo prolongado de su ocupación, a la fecha 37 años. Aún aceptando que deban aplicarse las normas de ocupación, surge la cuestión de la pertinencia de estas normas en relación a los problemas prácticos que ocurren en una ocupación prolongada, y si la instrumentación de estas normas sólo sirve a los propósitos de Israel. ${ }^{43}$ Cualquiera que sea la respuesta, está claro que la instrumentación del Cuarto Convenio de Ginebra debe favorecer la protección individual de los habitantes de los territorios ocupados.

38 Véase Shamgar, M., "The Observance of International Law in the Administered Territories", Israel Yearbook of Human Rights, núm. 1,1971, pp. 262-277.

39 Véanse los casos en el juicio Beit, op. cit., nota 35 y en el Elon Moreh, H. C. 390/79.

40 Roberts, "Prolongued...", cit., nota 2, p. 49.

41 Véase $o p$. cit., nota 5.

42 Para un análisis de la problemática derivada de una ocupación prolongada véase Portilla, op. cit., nota 8, pp. 193-195.

43 Roberts, A., "Prolongued...", cit., nota 2, p. 26. 


\section{G. Ocupación fiduciaria}

Las normas internacionales y las instituciones, incluyendo las Naciones Unidas, han reconocido la realidad de que ciertos territorios y pueblos no son autónomos y que potencias extranjeras pueden ejercer ciertas funciones de carácter fiduciario en tales territorios. ${ }^{44}$ La idea de que la ocupación por Israel de la Ribera Occidental pueda ser un tipo de "ocupación fiduciaria" ha sido planteada por Gerson. ${ }^{45}$ Este autor sostiene que debido a que los derechos de soberanía de Israel sobre la Ribera Occidental no son superiores a los de Jordania o a los de la población nativa, su condición es de ocupante, no de soberano legítimo. Esto dejaría a la población palestina con la posibilidad de alguna forma de autonomía después de un eventual arreglo negociado. Sin embargo, el carácter prolongado de la ocupación ha hecho de Israel un "ocupante fiduciario" más que un "ocupante beligerante". ${ }^{46} \mathrm{El}$ efecto de este argumento es dar a Israel mayor discreción que la conferida por el Cuarto Convenio de Ginebra, ya que cesa su carácter de "ocupante beligerante". Este argumento no tiene sustento en la doctrina y carece de reconocimiento como status territorial por los organismos internacionales competentes. ${ }^{47}$ Por otra parte, se ha señalado que hay un elemento fiduciario en todo derecho de ocupación. ${ }^{48}$

\section{H. La teoría del mandato continuo}

Finalmente, el punto de vista de Rostow es que el fracaso de la comunidad internacional en lograr una solución final al status territorial de la Ribera Occidental y Gaza resulta en la continuación del mandato sobre Palestina el cual autorizaría a los judíos a establecerse en el territorio bajo mandato, lo cual incluye a la Ribera Occidental. ${ }^{49}$ Este autor sostiene que la Declaración Balfour de 1917, misma que fue repetida en 1922 por el mandato de la Liga de las Naciones, es el derecho aplicable a los

44 Véase la Carta de las Naciones Unidas, artículos 73-85.

45 Gerson, A., "Trustee-Occupant: The Legal Status of Israel's Presence in the West Bank", Harvard International Law Journal, núm. 14, 1973, p. 1.

46 Falk y Weston, op. cit., nota 16, p. 132.

47 Ibidem, p. 133.

48 Roberts, A., "What is Military Occupation", British Yearbook of International Law, núm. 55, 1984, p. 295.

49 Rostov, E. V., "Palestinian Self-Determination: Posible Futures for the Unallocated Territories of the Palestinian Mandate", Yale Studies in World Public Order, núm. 5, 1979, p. 147. 
territorios ocupados, más que el Cuarto Convenio de Ginebra o el derecho de ocupación beligerante. ${ }^{50}$ Este argumento ignora tanto los actos de terminación de Gran Bretaña como potencia mandante ${ }^{51}$ como la Resolución 181 de la Asamblea General de la ONU, ${ }^{52}$ la cual por sí misma provee una de las bases legales más firmes para el propio status de Israel como Estado soberano. ${ }^{53}$

\section{El CUARTO CONVENIO DE GINEBRA COMO DERECHO CONSUETUDINARIO}

Un Estado debe ajustar explícitamente su sistema legal a fin de incorporar sus obligaciones derivadas de tratados internacionales al derecho interno. Israel no tiene incorporación automática sino legislativa del derecho internacional. El Knesset tiene que emitir legislación para instrumentar internamente un tratado y no ha hecho lo propio con los Convenios de Ginebra. ${ }^{54}$ De esto se explica que no pueda invocarse el Cuarto Convenio de Ginebra ${ }^{55}$ en un tribunal israelí.

Por lo que se refiere al Reglamento de La Haya, ${ }^{56}$ Israel acepta que es parte del derecho consuetudinario internacional y que se puede invocar en sus tribunales sin requerirse de ninguna legislación especial, salvo que se oponga a alguna otra disposición en derecho internacional. ${ }^{57}$ Por otra parte, la Suprema Corte de Israel ha rechazado que el Cuarto Convenio de Ginebra, o artículos específicos del mismo, formen parte del derecho consuetudinario internacional de modo que pueda ser aplicado por

50 Falk y Weston, op. cit., nota 16, p. 132.

51 En febrero de 1948, Inglaterra decidió abandonar su mandato y retirar sus tropas el 15 de mayo de ese año. Véase Osmañczyk, Edmund J., Enciclopedia mundial de relaciones internacionales y Naciones Unidas, México, FCE, 1976, p. 848.

52 Mediante la resolución 181/II del 29 de noviembre de 1947, la Asamblea General decidió la partición de Palestina en dos Estados independientes: uno árabe y otro judío, y de un régimen internacional autónomo para la ciudad de Jerusalén, bajo la autoridad de las Naciones Unidas. Véase idem.

53 Falk y Weston, op. cit., nota 16, p. 133.

54 Peleg, I., Human Rights in the West Bank and Gaza, Syracuse, N. Y., Syracuse Univerasity Press, 1995, p. 14.

55 Cuarto Convenio de Ginebra sobre la Protección de Personas Civiles en Tiempo de Guerra, adoptado el 12 de agosto de 1948, entrada en vigor el 21 de agosto de 1950, 75 UNTS, p. 287.

56 Convención sobre las Leyes y Costumbres de Guerra Terrestre, 18 de octubre de 1907, TS. núm. 539.

57 Casos Hilu, HC 302/72 y Beit, op. cit.. nota 35. 
tribunales internos, estableciendo que es sólo parte del derecho convencional internacional. ${ }^{58}$

Rubin sostiene que no es correcta la distinción que hacen los tribunales israelíes entre el Reglamento de La Haya y los Convenios de Ginebra. ${ }^{59}$ Dicho autor señala que las leyes de guerra de Inglaterra son parte de las leyes del la "tierra", ya sean de derecho consuetudinario o convencional, y así deben verse los Convenios de Ginebra como parte del derecho de la "tierra" en Israel también. Argumenta que no hay necesidad de una distinción entre el Convenio de Ginebra y el derecho consuetudinario y concluye que el Cuarto Convenio de Ginebra debe considerarse como parte del derecho interno de Israel y que la Suprema Corte debe regirse de acuerdo con él. Estos argumentos no han sido aceptados por Israel.

Un número importante de expertos en derecho internacional han expresado su punto de vista de que los Convenios de Ginebra son ahora parte del derecho consuetudinario. Esto se desprende de la alta cifra de Estados parte en los mismos ${ }^{60}$ y del carácter que han adquirido en la comunidad internacional. En 1993, un informe del secretario general de las Naciones Unidas al Consejo de Seguridad sobre el establecimiento del Tribunal Penal Internacional para la ex Yugoslavia indicó que el derecho contenido en los cuatro Convenios de Ginebra es parte integrante del derecho consuetudinario internacional. ${ }^{61}$

Es un hecho incontrovertible que ciertas disposiciones del Cuarto Convenio de Ginebra son parte del derecho consuetudinario, en tanto que muchos de sus artículos sólo reafirman disposiciones contendidas en el Reglamento de La Haya, las cuales son aceptadas por todos con carácter de derecho consuetudinario. El juez Witkon aceptó que el Cuarto Convenio de Ginebra es aplicable a la Ribera Occidental cuando dijo: "Es un error pensar... que el Convenio de Ginebra no aplica a Judea y Samaria. Aplica aún y cuando no sea justiciable en este tribunal". ${ }^{62}$ Se ha argu-

58 Qupty, M., "The Application of Internacional Law in the Occupied Territories as Reflected in the Judgements of the High Court of Justice in Israel", en Palyfair, E. (ed.), International Law and Administration, cit., nota 2, p. 111.

59 Rubin, B., "The Adoption of Internacional Conventions by Israeli Courts" (en hebreo), Meshpatiem 13 (1983), 210, pp. 210 y 211, citado en Qupty, op. cit., nota 58, p. 114.

60 Actualmente 191 Estados parte.

61 Roberts, A. y Guelff, R., Documents on the Laws of War, 3a. ed., Oxford, Oxford University Press, 2000, p. 196.

62 Caso Elon Moreh, HC 390/79, 29. 
mentado también que el Cuarto Convenio de Ginebra es parte del derecho israelí sobre la base de que está incluido entre las ordenanzas emitidas por el comando general. Esta idea surgió de un comentario hecho por el juez Barak en el caso Cooperativa de Vivienda de los Maestros, ${ }^{63}$ en el que dijo que el convenio no sólo constituye normas de suyo obligatorias, ya que el gobierno de Israel había decidido actuar de conformidad con él, sino también por ser parte de los lineamientos internos del gobierno a los mandos militares y por ser lineamientos independientes del propio comando general. Sin embargo, el problema es que estos lineamientos pueden cambiarse muy fácilmente sin requerirse su publicación. ${ }^{64}$

La práctica de aplicar únicamente el derecho consuetudinario internacional como parte del derecho israelí se ha vuelto tan enraizada que es improbable que pueda cambiarse. La única forma posible de avanzar en este sentido es promover la aceptación de la naturaleza consuetudinaria del convenio entre la comunidad internacional de modo que Israel la acepte también como tal.

\section{APLICACIÓN DEL DERECHO DE LOS DERECHOS HUMANOS EN LOS TERRITORIOS PALESTINOS OCUPADOS ${ }^{65}$}

El Reglamento de La Haya y el Cuarto Convenio de Ginebra representan un nivel de protección de derechos humanos diferente al previsto en tratados como el Pacto Internacional de Derechos Civiles y Políti$\cos ^{66}$ Por eso nuestro énfasis es más bien en la preservación de estándares humanitarios mínimos a través de la prohibición de represalias y castigos en contra de la población civil del territorio ocupado, así como la toma de rehenes, tortura, tratos inhumanos y degradantes, deportación, trabajo esclavo, requisa de propiedad, entre otros. ${ }^{67}$ Frente a la negativa israelí de aplicar de jure el cuarto convenio en los territorios palestinos

63 Caso Cooerativa de Vivienda de los Maestros. HC 393/82, 793-4

64 Qupty, op. cit., nota 58, pp. 118 y 119

65 Para un análisis detallado de la aplicación del derecho de los derechos humanos a territorios ocupados, véase Portilla, op. cit., nota 8, pp. 195-200.

66 Pacto Internacional de Derechos Civiles y Políticos, adoptado el 16 de diciembre de 1966, entró en vigor el 23 de marzo de 1976, 999 UNTS 171

67 Greenwood, C., "The Administration of Occupied Territory in Internacional Law", en Playfair, E. (ed.), The Administration of Ocupied Territory, p. 250. 
ocupados, la protección otorgada por los instrumentos de derechos humanos reviste la mayor importancia.

Aunque las convenciones de derechos humanos proveen sus propios mecanismos, su aplicación en los territorios ocupados es complicada. A menudo Israel ha argumentado que dichas normas no pueden aplicarse a una situación de ocupación. Esto contrasta con la posición de la comunidad internacional en el sentido de que si bien los dos cuerpos normativos son conceptualmente diferentes se complementan uno al otro y pueden aplicarse paralelamente en la mayoría de las situaciones de conflicto. ${ }^{68}$ Sin embargo, esto no resuelve muchos de los problemas prácticos en torno a la aplicación de derechos humanos en tales situaciones. Estos problemas se presentan al plantearse la relevancia de estas normas en situaciones de conflicto armado y las dificultades que surgen de la diferencia entre derechos humanos y derechos humanitarios respecto a cuestiones como el uso de la fuerza letal y el derecho a un juicio justo. Mientras que el derecho de los derechos humanos dispone el derecho a la vida y a ser en procesado justamente, el derecho humanitario dispone el derecho a disparar a los combatientes y a no tener un juicio en determinados casos. ${ }^{69}$

Una convención requiere ser ratificada para ser aplicable. Aunque Israel ha ratificado las principales convenciones internacionales sobre derechos humanos, éstas técnicamente deben ser promulgadas internamente para ser justiciables, y esto no ha sucedido. Como resultado, los tribunales israelíes no se han apoyado en ellos. A pesar de su ratificación, se cuestiona si ésta abarca los territorios ocupados y los términos de cada tratado deben examinarse para determinar su alcance. ${ }^{70}$ Un buen ejemplo es el Pacto Internacional de Derechos Civiles y Políticos ratificado por Israel en 1991. El artículo 2 del convenio señala: "Cada Estado Parte en el Pacto se compromete a respetar y asegurar a todos los individuos dentro de su territorio y someter a su jurisdicción los derechos reconocidos en el presente Pacto".

Esta disposición no deja lugar a dudas sobre la aplicación del Pacto a los territorios ocupados de Palestina.

68 Kalin, W., Human Rights in Times of Occupation: The Case of Kuwait, Beirne, Law Books in Europe, 1994, pp. 26 y 27. Véase Portilla, op. cit., nota 8, pp. 75-79

69 Bell, C., Peace Agreements and Human Rights, Oxford University Press, 2000, p. 80

70 Idem. 
Las instancias internacionales relacionadas con esta cuestión sostienen que Israel es responsable respecto a la aplicación de los instrumentos de derechos humanos en todas las zonas donde mantiene jurisdicción, geográfica, funcional o personal. ${ }^{71}$ En sus consideraciones sobre el informe inicial de Israel, el Comité sobre Derechos del Niño inquirió sobre el trato de Israel a los niños en los territorios ocupados. Demandó saber por qué el informe de Israel no contenía ninguna información sobre la instrumentación de la Convención de los Derechos del Niño en los territorios ocupados. ${ }^{72}$ Esto denota que el comité consideró aplicable dicho instrumento en los territorios ocupados.

De manera similar, el Informe 2002 del Relator Especial de la Comisión de Derechos Humanos sobre la situación de los derechos humanos en los territorios palestinos ocupados por Israel desde 1967 elaboró un detallado análisis sobre la violación de los derechos humanos de la población de los territorios ocupados vinculándola con los diversos instrumentos aplicables de derechos humanos. ${ }^{73}$ Señaló que los instrumentos de derechos humanos complementan el Cuarto Convenio de Ginebra al definir y dar contenido a los derechos protegidos en su artículo 27, indicando de tal modo que estos instrumentos aplican en los territorios palestinos ocupados. ${ }^{74}$

Por su parte, el Comité de Derechos Humanos al considerar el segundo informe periódico en 2003 de acuerdo con el Pacto Internacional de Derechos Civiles y Políticos cuestionó las decisiones del la administración israelí y las acciones de sus fuerzas armadas en los territorios palestinos ocupados. ${ }^{75}$ Dichas indagaciones se han vuelto comunes dentro del monitoreo internacional de derechos humanos y reafirman la posición de que estos instrumentos aplican en los territorios ocupados. Sin duda, todo ello puede tener un efecto positivo sobre el comportamiento de Israel en el largo plazo.

$71 \quad$ Ibidem, p. 81.

$7214 / 06 / 2002, \mathrm{CRC} / \mathrm{C} / \mathrm{Q} / \mathrm{ISR} / 1$

73 Dugard, J., Question of the violation of human rights in the occupied Arab territoriews, including Palestine, Informe del Relator Especial de la Comisión de Derechos Humanos sobre la situación de los derechos humanos en los territorios palestinos ocupados por Israel desde 1967, A/57/366.

74 Ibidem, p. 9

$75 \mathrm{HR} / \mathrm{CT} / 6349,15$ de julio del 2003. 


\section{EL MURO ISRAELÍ EN TERRITORIO PALESTINO}

\section{Terminología}

Hay notorias diferencias en la terminología para referirse a la barrera que Israel se encuentra construyendo en la Ribera Occidental. Los palestinos hablan de "muro de separación", mientras que los israelíes utilizan la palabra "valla de seguridad". En su opinión consultiva, la Corte Internacional de Justicia ${ }^{76}$ se refiere al "muro", empleando el mismo término que la Asamblea General. Por su parte, el secretario general de la ONU en su informe a la Asamblea General adoptó el término más general de "barrera". 77

\section{La construcción del muro}

El 14 de abril del 2002, el gabinete israelí anunció la construcción de "cercas y otros obstáculos físicos" para prevenir el paso de los palestinos a Israel. El anuncio, hecho durante la campaña "escudo defensivo" tras una serie de ataques suicidas en contra de civiles israelíes, indicaba que se crearían "zonas de amortiguamiento" en tres sectores a lo largo de la Línea Verde, la línea de demarcación posterior a 1948 entre Israel y la Ribera Occidental. ${ }^{78}$ Conforme a lo planeado, en junio del 2002, comenzó la construcción de un gran complejo de zanjas, muros y cercas. Dicho complejo comprende los siguientes elementos: ${ }^{79}$

- Una valla de sensores electrónicos.

- Una zanja de hasta cuatro metros de profundidad.

- Una carretera asfaltada de dos carriles para patrullas.

- Un camino de arena allanada para detectar huellas, que discurre en paralelo a la valla.

76 Opinión Consultiva de la Corte Internacional de Justicia sobre las consecuencias jurídicas de la construcción de un muro en el territorio palestino ocupado, 9 de julio del 2004, Corte Internacional de Justicia, Lista general núm. 131, http:/wwww.icj-cij.org

77 Véase General Assembly, Report of the Secretary General Prepared Pursuant to General Assembly Resolution ES-10/13, UN Document No. A/ES-10/248, 24 de noviembre del 2003.

78 Human Rights Watch, "West Bank Barrier Endagers Basic Rights", HRW Documents on Israel/PA, http:/www.hrw.com

79 Este listado es el proporcionado por el informe del secretario general y el mismo que recoge la Corte Internacional de Justicia en su Opinión Consultiva, op. cit., nota 76, p. 32. 
- Seis rollos de alambre de púas apilados para marcar el perímetro de las instalaciones.

Según informes del gobierno de Israel, la anchura promedio del muro es de 50 metros y en algunos puntos se duplica esa cantidad. ${ }^{80} \mathrm{De}$ acuerdo con fuentes palestinas, la longitud proyectada del muro varía entre 752 y 788 kilómetros. ${ }^{81}$ Ante la Corte Suprema Israelí, el gobierno declaró haber aprobado la construcción del muro en cuatro etapas con una longitud total de 626 kilómetros, aproximadamente. ${ }^{82}$

En algunas secciones, el muro corre a lo largo de la Línea Verde y en otras entra en la Ribera Occidental, afectando propiedades y aislando comunidades palestinas. Según estimaciones de la ONU sólo un $11 \%$ del perímetro del muro corre a través de la Línea Verde; 83 el resto del muro -incluyendo tanto las secciones ya construidas como las planeadas - se adentrará varios kilómetros sobre la Ribera Occidental. En el caso de Jerusalén, las instalaciones existentes y el trazado previsto estarían lejos de la Línea Verde y en algunos casos incluso lejos del límite municipal oriental de la ciudad fijado por Israel. ${ }^{84}$

Asimismo, en otras tramos del muro, sobre todo las que corren a lo largo de la Línea Verde, hay planes para un tramo adicional de varios kilómetros hacia el oeste, referido como la "barrera profunda". Ésta ha sido descrita por el gobierno de Israel como una "barrera sin una cerca y diseñada para dirigir el movimiento hacia puntos de control". ${ }^{85}$ Por otra parte, en el informe de B'Tselem se le describió como una zanja profunda con una malla de alambre de púas a lo largo de la misma. ${ }^{86}$

80 Ministry of Defense, Israel's Security Fence, http:/www.securityfence.mod.gov.il/Pages/ ENG/operational.htm

81 PLO, Negotiations Affair Deparment, Israel Security Wall: Bad Fences Make Bad Neighbors, diciembre de 2003.

82 Caso Hamoked v. Government of Israel, HCJ9961/03.

83 Véanse mapas de la ONU en United Nations Office for the Coordination of Humanitarian Affairs, http:/www.humanita rianinfo.org/opt

84 Esto significa que Israel estaría violando el Acuerdo de Armisticio entre Israel y Jordania en el que se fijó la línea de demarcación (la Línea Verde) entre ambos países. El artículo 3 se precisa que "ningún elemento de las fuerzas militares o paramilitares de ninguna de las partes...cruzará o atravesará, por ningún motivo, las líneas de demarcación del armisticio”. Además, Israel estaría ampliando su ocupación ilegal del sector oriental de Jerusalén.

85 Véase Ministerio de Defensa de Israel, op. cit, nota 80.

86 B'Tselem es una organización creada en 1989 por un grupo de prominentes académicos, abogados, periodistas y miembros del Knesset, www.btselem.org/Download/200304_Behind_The_ Barrier_Eng.pdf 
La barrera incluye un limitado número de accesos para permitir el cruce de personas y bienes, así como otros para ingresar a tierras de cultivo. Las secciones concluidas del muro contienen cinco accesos para el cruce de personas y bienes, y se planea incluir 26 para ingresar a tierras de cultivo, cinco de las cuales se ubicarían a lo largo de la "barrera profunda". 87

Se estima que las secciones concluidas del muro han confinado al menos a 12,000 palestinos entre el muro y la Línea Verde, impidiéndoles el acceso a servicios públicos y empleo. ${ }^{88}$ En octubre del 2002, el gobierno de Israel declaró esta área como una "zona militar cerrada". ${ }^{89}$ Se estima que la ruta del muro resultará en el aislamiento de alrededor de 128,500 palestinos del resto de la Ribera Occidental, así como unos de otros en enclaves sobre la parte oriental del muro. ${ }^{90}$ Asimismo, las secciones concluidas del muro han resultado en la destrucción de unos 8.4 kilómetros cuadrados de olivos y otros árboles frutales, 6.5 kilómetros cuadrados de tierras agrícolas de riego, 37.3 kilómetros cuadrados de mantos acuíferos, y 15 kilómetros de caminos agrícolas en los distritos de Jenin, Tukkarem y Qalqilya. ${ }^{91}$

\section{Ajustes en el trazo del muro}

En su decisión del 30 de junio del 2004, la Corte Suprema de Israel resolvió que una sección del muro debía modificarse debido a que implicaba excesivas privaciones a la población palestina. En acatamiento de dicha sentencia, el gabinete israelí aprobó, en su sesión del 21 de febrero del 2005, una nueva ruta en el tramo sur del muro. ${ }^{92}$ Según el gobierno de Israel, con este ajuste se reduce del 15 al 7\% la superficie afectada

87 Idem.

88 The Palestinian Independent Commission for Citizen's Rights, Creeping Annexation: The Israeli Separation Wall and its Impact on the West Bank, junio de 2003, p. 9.

89 IDF, IDF Forces Commander in the Judea and Samaria Region, Order Concerning Security Directives (Judea and Samaria), number 378, 1970; Declaration Concerning the Closure of area, núm. s/23/03 (Seam Area), 2 de octubre de 2003.

90 Informe B'Tselem, op. cit., nota 86.

91 World Bank, "Local Coordination Committee, Humanitarian and Emergency Policy Group", The Impact of Israel Separation Barrier on Affected West Bank Communities, 2 de mayo de 2003, p..33.

92 En dicha sesión se aprobó también el proyecto del retiro israelí de la Franja de Gaza, el cual comenzará en julio del 2005 y concluirá a finales del mismo año. 
dentro de la Ribera Occidental. ${ }^{93}$ Sin embargo, se deja del lado israelí un triple conjunto de importantes colonias, a saber: Ariel, entre Naplusa y Ramallah, Maalé Adoumim, al este de Jerusalén y Goush Etzion, al sur de la misma. ${ }^{94}$ Debido a la céntrica ubicación de estos asentamientos, la construcción del muro a su alrededor impactará severamente la libertad de movimiento de la población palestina en la Ribera Occidental. Aún quedan por desarrollarse nuevos planes que requerirán la aprobación del primer ministro y el ministro de Defensa. ${ }^{95}$

\section{LA OPINIÓN CONSULTIVA DE LA CORTE INTERNACIONAL DE JUSTICIA ${ }^{96}$}

\section{Solicitud de la Asamblea General}

El 8 de diciembre del 2003, en el curso de su décimo periodo extraordinario de sesiones de emergencia sobre la cuestión de Palestina, la Asamblea General de las Naciones Unidas adoptó, por 90 votos a favor, ocho en contra y 74 abstenciones, la Resolución ES-10/14 solicitando a la Corte Internacional de Justicia una opinión consultiva ${ }^{97}$ sobre las consecuencias legales derivadas de la construcción por Israel de un muro que separa partes de la Ribera Occidental de Israel. La pregunta formulada es la siguiente:

¿Cuáles son las consecuencias jurídicas que se derivan de la construcción del muro que levanta Israel, la Potencia ocupante, en el territorio palestino ocupado, incluida Jerusalén oriental y sus alrededores. Según se describe en el informe del Secretario General, teniendo en cuenta las normas y principios de derecho internacional, incluido el Cuarto Convenio de Ginebra de 1949 y las resoluciones pertinentes del Consejo de Seguridad y de la Asamblea General?

93 "Cabinet in Israel Ratifies Pullout From Gaza Strip", The New York Times, 21 de febrero de 2005, pp. 1-2, nytimes.com

94 "Le gouvernement israélien a approuvé le projet d'evacuation des colonies de Gaza", Le Monde, 21 de febrero de 2005, Le Monde.fr

95 B'Teselm, Separation Barrier, 23 de febrero de 2005: Barrier route updated, http:/www.betselem.org./separation barrier.

96 De conformidad con el artículo 39 del Estatuto de la Corte Internacional de Justicia, la opinión consultiva se emitió en inglés y francés. Sin embargo, la Asamblea General lo tradujo a los distintos idiomas oficiales de éste órgano, entre ellos el español.

97 De acuerdo con el artículo 96.1 de la Carta de las Naciones Unidas. 
El pronunciamiento del más alto tribunal internacional sobre este asunto ofrece una singular oportunidad de precisar el régimen jurídico de los territorios ocupados, a partir de dos rubros claves: la dicotomía entre el respeto a los derechos humanos de los palestinos y los intereses de seguridad de Israel, y la aplicación del Cuarto Convenio de Ginebra a la ocupación israelí de los territorios palestinos.

\section{La CIJ determinó que la construcción del muro viola el derecho internacional}

\section{A. Competencia y admisibilidad}

En la fase escrita de los procedimientos participaron 44 Estados miembros de la ONU (incluido Israel), la Liga Árabe, la Conferencia Islámica y la propia Palestina. ${ }^{98}$ Éstos tres últimos más 12 Estados pertenecientes a cuatro distintas regiones presentaron argumentos orales. Israel decidió no participar en esta fase.

La corte desechó el argumento israelí de que la Asamblea General había excedido su competencia de acuerdo con la carta debido al activo papel desempeñado por el Consejo de Seguridad en la cuestión palestina. Si bien este órgano, señaló la corte, tiene la responsabilidad primordial del mantenimiento de la paz, su función no es exclusiva y es compartida con la Asamblea General.

Asimismo, se refutó la solicitud de opinión consultiva aduciendo que la Asamblea General no podía reunirse en periodo extraordinario conforme a la Resolución 377 A (V) 99 en virtud de que al aprobar "la Hoja de Ruta", ${ }^{100}$ el Consejo de Seguridad había cumplido su función respecto al

98 Véase ICJ Communiqué 2004/5 (Feb. 3, 2004). La actuación de Palestina en la corte constituye un hecho sin precedentes ya que es la primera vez que un sujeto con status de observador en la Asamblea General de las Naciones Unidas participa en procedimientos consultivos.

99 De acuerdo con Jorge Castañeda, "esta resolución adoptada en 1950 a raíz de la guerra de Corea, representa el esfuerzo más serio que se ha intentado para eludir el principio de la unanimidad de los cinco miembros permanentes del Consejo de Seguridades la solución de situaciones que significan una amenaza grave a la paz, un quebrantamiento de la paz o un acto de agresión". En su parte conducente señala que de darse una situación como la descrita, "la Asamblea General examinará inmediatamente el asunto, con miras a dirigir a los miembros recomendaciones apropiadas para la adopción de medidas colectivas". Véase Castañeda, Jorge, México y el orden internacional, México, El Colegio de México, 1981, pp. 138-142

100 La Hoja de Ruta es un plan auspiciado por Estados Unidos que junto con la Unión Europea, Rusia y la ONU, forman el llamado Cuarteto. Está basado en la Conferencia de Madrid y en las resoluciones 242, 338 y 1397 del Consejo de Seguridad. Contempla 3 fases y en la última, en 2005, 
mantenimiento de la paz y seguridad internacionales. Al respecto, la corte observó que el Consejo de Seguridad había incumplido con su responsabilidad en esta materia como resultado del veto de uno de sus miembros permanentes y que la situación justificaba la aplicación de la citada resolución.

Ante el argumento de que este asunto carecía de sustento jurídico por tener una naturaleza esencialmente política, la corte respondió que los aspectos políticos y jurídicos de una cuestión internacional están estrechamente vinculados, sin que ello impida su competencia.

Aún sin apoyar la legalidad del muro, algunos participantes (sobre todo de Europa Occidental) cuestionaron la pertinencia de que la corte conociera del caso. Más la corte reafirmó su facultad discrecional en la materia al no haber razones que le impidieran proceder en tal sentido. La objeción de que la corte no puede resolver su diferendo con Palestina si Israel se opone a ello fue rechazada. La construcción del muro afecta la paz y la seguridad internacionales y no implica únicamente a las relaciones bilaterales entre Palestina e Israel; sino que interesa directamente a la ONU, la cual tiene una responsabilidad permanente sobre Palestina derivada del mandato y la resolución relativa a la partición de la misma.

Otra de las objeciones a la competencia de la corte fue en el sentido de que la opinión consultiva era inapropiada debido a que interfería con la solución negociada del conflicto palestino-israelí y podría afectar el proceso de la "Hoja de Ruta". Más aún, se señaló que la corte no disponía de evidencias suficientes para pronunciarse sobre estos hechos. A la primera objeción respondió que su único propósito consistía en determinar las consecuencias legales de la construcción del muro, y respecto a la segunda, contestó que el material con que contaba era suficiente para emitir la opinión solicitada en su carácter de órgano jurisdiccional.

También se manejó el argumento de que era innecesaria la opinión consultiva en virtud de que la Asamblea General ya había declarado ilegal al muro. La corte respondió que no le correspondía decidir si la Asamblea General tenía o no necesidad de dicha opinión ya que este órgano decide por si mismo de acuerdo con sus propias necesidades.

El último alegato de competencia sostenido por Israel consistió en atribuir responsabilidad a Palestina por los actos violentos que conduje- 
ron a la construcción del muro de tal modo que era improcedente que ésta solicitase a la corte pronunciarse sobre una situación que ella misma había contribuido a crear. A tal pretensión israelí, la corte respondió que era la Asamblea General la que había solicitado dicha opinión y no un Estado o ninguna otra entidad, y por tanto es a ese órgano a quien deberá dirigirse.

\section{B. Estatus del territorio y derecho aplicable}

Una vez que la corte desechó las pretensiones de competencia y admisibilidad, avanzó hacia su objetivo central: determinar las consecuencias jurídicas de la construcción del muro. Para ello tuvo que reseñar los avatares históricos de la región a partir de la disolución del imperio otomano, pasando por el mandato británico de 1922 y concluyendo con los distintos episodios bélicos que, de 1947 a 1967, han modelado el mapa de Palestina.

Del conjunto de elementos analizados, la corte determinó que el área en cuyo interior se ubica el muro es un territorio bajo ocupación militar conforme al derecho internacional. Siendo así, se aplica la totalidad de los instrumentos jurídicos internacionales que regulan los conflictos armados. Asimismo, se precisó la obligación israelí de observar sin restricciones el derecho internacional humanitario, representado por el Reglamento de La Haya de 1907 y por el Cuarto Convenio de Ginebra de 1949.

De igual modo, las convenciones internacionales relativas a derechos humanos, reconocidas por Israel, fueron declaradas aplicables por la corte al territorio palestino ocupado. Esto desechó la pretensión israelí de excluir el régimen de derechos humanos a situaciones de ocupación y aplicar exclusivamente el derecho humanitario. La corte rechazó esta peligrosa tesis y confirmó que la protección otorgada por estas convenciones no cesa en tiempos de conflicto armado. En consecuencia, se condenó la violación a las normas e instrumentos internacionales antes señalados por la construcción del muro. Entre las violaciones más graves, destacan: el confinamiento territorial, el traslado de civiles israelíes a territorio ocupado, la destrucción y requisa de propiedades, la obstrucción a la libertad de circulación y el deterioro socio-económico de la población palestina. 
La corte consideró que la construcción del muro y su régimen conexo crean un "hecho consumado" que bien podría ser permanente, en cuyo caso equivaldría a una anexión de facto. Asimismo, determinó que esa construcción, junto con las medidas tomadas anteriormente, menoscaba gravemente el ejercicio por el pueblo palestino de su derecho a la libre determinación y constituye en consecuencia una violación de la obligación de Israel de respetar ese derecho.

Al rechazar las excepciones planteadas por Israel en el sentido de ignorar en ciertas situaciones la aplicación de los regímenes de derechos humanos y del derecho humanitario, la corte desestimó la forma que Israel eligió para lograr sus objetivos de seguridad. Según ésta, el muro, a lo largo de la ruta trazada, y su régimen conexo "infringen gravemente diversos derechos de los palestinos que residen en el territorio ocupado por Israel y las infracciones derivadas de ese trazado no pueden justificarse por necesidades militares, de seguridad nacional o de orden público."

En relación con el planteamiento israelí de que la construcción del muro es consistente con el artículo 51 de la Carta de la ONU que preceptúa la legítima defensa, la corte determinó que esta disposición es irrelevante para este caso porque los ataques en su contra no provienen de un Estado extranjero. Por ello no es posible hablar de legítima defensa en tanto la violencia se genera al interior de un territorio bajo su control.

Por otra parte, aunque la corte reconoció el derecho de Israel a responder en contra de los ataques a su población civil a fin de proteger la vida de sus nacionales, precisó que las medidas emprendidas deben estar en consonancia con el derecho internacional aplicable.

En otro intento de justificar la construcción del muro, Israel planteó un estado de necesidad para derogar los derechos de los palestinos al no disponer de otros medios para protegerse. Esta pretensión fue rechazada por la corte aduciendo que la construcción del muro no constituía el único medio de protección disponible por Israel.

En suma, la corte descartó categóricamente la legítima defensa y el estado de necesidad como excluyentes de ilicitud en este caso. Siendo así, determinó que la construcción del muro, y su régimen conexo, contravienen el derecho internacional. 


\section{Consecuencias jurídicas}

En este punto la corte procedió a dar una respuesta concreta a la pregunta planteada por la Asamblea General y constituyó el núcleo mismo de su opinión consultiva. Para tal efecto, se recurrió a la aplicación de una figura fundamental como la responsabilidad internacional para determinar las consecuencias legales para Israel, así como para otros Estados, y las propias Naciones Unidas.

\section{A. Consecuencias jurídicas para Israel}

Al encontrar que las violaciones de Israel generaban la responsabilidad de éste bajo el derecho internacional, la corte determinó que Israel: a) Está obligado a cumplir su obligación de respetar el derecho del pueblo palestino a la libre determinación y sus obligaciones con el derecho internacional humanitario y el derecho internacional de los derechos humanos; b) Debe asegurar la libertad de acceso a lo lugares sagrados que quedaron bajo su control luego de la guerra de 1967; c) Tiene la obligación de poner fin a la violación de sus obligaciones internacionales referentes a la construcción del muro en el territorio palestino ocupado; d) Tiene la obligación de detener de inmediato las obras de construcción del muro que está levantando en el territorio palestino ocupado, incluida Jerusalén oriental y sus alrededores, y debe desmantelar las instalaciones de dicha estructura; e) Debe derogar o dejar sin efecto todos los actos legislativos y reglamentarios adoptados con miras a la construcción del muro, salvo en la medida que dichos actos prevean una compensación u otras formas de reparación para la población palestina; f) Tiene la obligación de reparar los daños causados a todas las personas físicas o morales afectadas, ya sea devolviendo las tierras, huertos, olivares y demás bienes inmuebles de los que haya despojado a cualesquiera personas físicas o morales a los efectos de la construcción del muro en el territorio palestino ocupado o, si tal restitución es materialmente imposible, a compensar a dichas personas por el daño sufrido, y g) Tiene la obligación de compensar a todas las personas físicas o morales que hayan sufrido cualquier forma de daño material como resultado de la construcción del muro. 


\section{B. Consecuencias jurídicas para otros Estados}

En relación a las consecuencias jurídicas para otros Estados, la corte determinó que entre las obligaciones violadas por Israel hay algunas con la categoría erga omnes, a saber: el derecho del pueblo palestino a la libre determinación, así como ciertas obligaciones israelíes bajo el derecho internacional humanitario, las cuales deben ser observadas por todos los Estados debido a que constituyen principios intransgredibles de derecho internacional consuetudinario. De acuerdo con la corte, todos los Estados tienen la obligación de no reconocer la situación ilegal resultante de la construcción del muro en el territorio palestino ocupado, incluida Jerusalén oriental y sus alrededores. Asimismo, todos los Estados están obligados a no prestar ayuda ni asistencia para el mantenimiento de la situación creada por tal construcción, y deben velar porque se ponga fin a todo impedimento, resultante de la construcción del muro, para el ejercicio por el pueblo palestino de su derecho a la libre determinación. En este sentido, se desprende del artículo 1 del Cuarto Convenio de Ginebra que todo Estado parte en el mismo, sea o no parte en un conflicto determinado, tiene la obligación de hacer que se cumplan las exigencias impuestas por los instrumentos en cuestión. Por ello, todos los Estados partes del Cuarto Convenio de Ginebra tienen la obligación de hacer que Israel respete el derecho humanitario incorporado en dicho convenio.

\section{Consecuencias jurídicas para las Naciones Unidas}

Respecto a las consecuencias jurídicas para las Naciones Unidas, según la corte esta organización, "y especialmente la Asamblea General y el Consejo de Seguridad, deberían considerar que medidas adicionales son necesarias para poner fin a la situación ilegal resultante de la construcción del muro y el régimen conexo, teniendo debidamente en cuenta la presente Opinión Consultiva".

Finalmente, la corte enfatizó "la urgente necesidad de que las Naciones Unidas en conjunto redoblen sus esfuerzos por lograr una rápida conclusión del conflicto israelo-palestino, que sigue planteando una amenaza para la paz y la seguridad internacionales, y establecer de tal forma una paz justa y duradera en la región". 


\section{CONCLUSIONES}

Israel ha tratado de probar de diversas maneras que la ocupación de los territorios palestinos constituye un régimen excepcional que excluye la aplicación de algunas disposiciones del derecho humanitario. Sus argumentos se han expresado mediante interpretaciones dudosas del cuerpo legal convencional y consuetudinario relativo al derecho de la ocupación beligerante.

Israel ratificó el Cuarto Convenio de Ginebra en 1951 y sin embargo rechaza su aplicación a los territorios palestinos ocupados basándose en diversos criterios, algunos de ellos contradictorios entre sí mismos. El no reconocimiento de Israel del carácter de derecho consuetudinario del convenio es un medio de eludir sus obligaciones para instrumentarlo, ya que el Knesset sólo tiene que incorporarlo en su derecho interno a fin de hacerlo aplicable a los territorios palestinos ocupados. La disposición de Israel de aceptar las "disposiciones humanitarias" del convenio ha demostrado ser una promesa incumplida a la luz de sus políticas emprendidas las cuales resultan en serias y reiteradas violaciones al convenio.

Las ocupaciones militares prolongadas evidencian ciertas deficiencias en el derecho de la ocupación beligerante. Algunas de sus disposiciones carecen de precisión en virtud de que fueron diseñadas para cubrir una gran variedad de situaciones. No obstante ello, el argumento de que el territorio ocupado es sui generis no lleva a la conclusión de que la administración israelí tenga mayores poderes, sino que se vuelve obligatoria la aplicación de un rango más amplio de derechos humanos por parte de la potencia ocupante. En este sentido, Israel ha desarrollado una política que desafía las disposiciones humanitarias del Reglamento de La Haya y el Cuarto Convenio de Ginebra, así como de diversos tratados de los cuales es parte.

Muchos de los instrumentos de derechos humanos aplican a los territorios palestinos ocupados, aunque los términos de cada tratado requieren ser examinados en detalle para determinar su alcance. Una supervisión a través de órganos de monitoreo respecto a la situación de los derechos humanos de la población civil en los territorio palestinos ocupados ofrece la mejor opción para disminuir las violaciones en el futuro inmediato.

La construcción de un muro de separación en Cisjordania viene a sumarse a la permanente violación de Israel al derecho internacional res- 
pecto a la ocupación de los territorios palestinos. Anunciada como una valla protectora para impedir los ataques terroristas de grupos extremistas palestinos, ésta constituye un auténtico muro que supera en dimensiones al extinto Muro de Berlín pues lo duplica en longitud y lo triplica en altura. Su trazo no sigue, como muchos piensan, el perímetro de la Línea Verde sino que se adentra varios kilómetros hacia el este, al interior de Cisjordania. Esto significa que alrededor del $90 \%$ del muro se ubica en territorio palestino dentro de Cisjordania, rodeando a localidades y pueblos palestinos, aislando entre sí comunidades y familias. Además, separa a los palestinos de sus tierras de labranza, escuelas y hospitales.

Hasta ahora, se ha completado más de la mitad del muro, principalmente en el área septentrional de Cisjordania y alrededor de Jerusalén. En el levantamiento del muro, el ejército israelí ha destruido extensas zonas de fértiles tierras de cultivo palestinas y otras zonas más grandes han quedado aisladas del resto de Cisjordania.

El diseño del muro permitirá la inclusión de un número considerable de asentamientos israelíes ubicados dentro de los territorios ocupados de tal suerte que más de 320 mil colonos israelíes, que representan el 80\% de los colonos que viven en los territorios ocupados, quedarán en la parte oeste del muro, con lo que tendrán una mayor contigüidad territorial con Israel.

Si bien no se cuestiona el derecho de Israel a la protección de sus nacionales y a la seguridad de sus fronteras, la construcción de un muro dentro de los territorios ocupados viola el derecho internacional en una doble vertiente, a saber: el derecho humanitario y el derecho de los derechos humanos. La instalación del muro en Cisjordania y en Jerusalén Oriental y sus alrededores, no es una respuesta de la administración de Ariel Sharon a los ataques terroristas sino que constituye un plan bien definido para anticiparse a la creación del Estado Palestino (previsto en la propia Hoja de Ruta para el 2005). ${ }^{101}$ Así cuando llegue ese momento,

101 En este sentido nos señala Joshua Hammer: "Israel politicians and human-rights groups say that if the partitions are finished, they will effectively divide Palestinian territory into three is- lands cut off from one another by Jewish settlements blocks. The total amount of land reserved for Palestinians would be about 42 per cent of the West bank - roughly equivalent to what Sharon has offered for a Palestinians state in the past- - Hemmed in by fences this truncated state would pose no security threat and be completely dependent on Israel for water, commerce and its very survival. "Sharon showed me a map (of the scheme) 25 years ago", says Ron Nachman, the mayor of Ariel, who spearheaded the drive to enclose his settlement in the israeli military's security fence. "His idea was to cut the region in three parts. That idea hasn't changed", http:wwwkeepmedia.com/. 
las fronteras internacionales reconocidas entre Palestina e Israel habrán sido modificadas unilateralmente por éste, por vía de mayores anexiones de facto, amén del cambio demográfico que se produciría con la transferencia de población israelí, especialmente ahora que muchos de los colonos desalojados de Gaza podrían reubicarse en Cisjordania.

Ante la ilegalidad de la construcción del muro y su régimen conexo, la Asamblea General de las Naciones Unidas, representando la mayoría de la comunidad internacional, solicitó a la Corte Internacional de Justicia una opinión consultiva sobre las consecuencias jurídicas de tal acción de Israel. En los procedimientos ante la corte actuó un variado número de Estados y organizaciones internacionales, destacándose la participación de Palestina, a través de su delegado ante la ONU, siendo éste un hecho sin precedentes por tratarse de un sujeto con carácter de observador permanente. Tras determinar su competencia desechando diversos argumentos, que se oponían al conocimiento por la corte del caso, la Corte de La Haya procedió precisar el status del territorio y el derecho aplicable. Para ello, la corte desechó las pretensiones israelíes de justificar el muro con base en figuras como la legítima defensa o el estado de necesidad.

En la parte medular de su opinión consultiva, la corte respondió a la pregunta formulada basándose en la responsabilidad internacional y de ahí derivar en tres tipos de consecuencias jurídicas de acuerdo con sus destinatarios, a saber: Israel, otros Estados y las propias Naciones Unidas. Respecto al primero, determinó que la construcción del muro en la Cisjordania ocupada, incluido Jerusalén Oriental y sus alrededores, viola el derecho internacional humanitario y de derechos humanos, y que Israel tiene la obligación de poner fin a la violación sus obligaciones internacionales derivada de la construcción del muro en los territorios palestinos ocupados. Asimismo, concluyó que Israel debe reparar el daño causado hasta ahora, señalando el principio de que la reparación debe subsanar, en la medida de lo posible, todas las consecuencias del acto lícito. En relación con otros Estados, tras destacar el carácter erga omnes de algunas de las obligaciones violadas por Israel, la corte señaló la obligación que tienen todos los Estados de no reconocer la situación ilegal

pubs/Newsweek/2003/06/09/30762. Para un mayor análisis de las implica ciones expasionistas del sionismo y del los planes de Sharon respecto al muro, véanse: Brubacher, Mathew, "De L'Antiterrorisme à la guerre, Le mur de la honte", Le Monde Diplomatique, 3 de enero de 2003, p. 20, y Algaza, Gadi, "La vrai "Feuille de Route" du Gouvernement Israélien. Un Mur pour enfermer les Palestiniens", Le Monde Diplomatique, agosto de 2003, p. 10. 
resultante de la construcción del muro en el territorio palestino ocupado. Por cuanto a las consecuencias jurídicas para la ONU, ésta, y especialmente la Asamblea General y el Consejo de Seguridad, deben estudiar que otras medidas son necesarias para poner fin a la situación ilegal que se produce como consecuencia de la construcción del muro.

En la historia del conflicto de Palestina se han presentado un sinnúmero de planes de paz y diversos esfuerzos diplomáticos. Se han intentado acciones de diversa índole que van desde negociaciones multilaterales respaldadas por las grandes potencias hasta el diálogo directo entre palestinos e israelíes. Se han logrado avances mínimos y la espiral de violencia entre unos y otros continúa. Sin embargo, esta es la primera ocasión en que se solicita un dictamen legal a un tribunal internacional y esto constituye una oportunidad única de que se analice esta cuestión bajo la óptica del derecho internacional más allá de las consideraciones geopolíticas presentes en otras instancias.

No obstante las limitaciones inherentes a una opinión consultiva, la resolución de la Corte Internacional de Justicia posee un gran valor legal por cuanto al responder la pregunta formulada por la Asamblea General precisa con exactitud el régimen jurídico internacional aplicable a la $\mathrm{Ri}$ bera Occidental y Jerusalén Oriental, y pone de manifiesto las violaciones de Israel en la construcción del muro. Desde nuestro punto de vista, las conclusiones que se obtienen de esta opinión consultiva no sólo son válidas respecto a la problemática sobre el muro y su régimen conexo en particular sino también a la ocupación de los territorios palestinos en general. 